\title{
What Factors are Responsible for Higher Prevalence of HIV Infection among Urban Women than Rural Women in Tanzania?
}

\author{
Rakesh K. Singh ${ }^{1}$, Shraboni Patra ${ }^{1}$
}

\begin{abstract}
BACKGROUND: Tanzania is the country hit the hardest by the HIV epidemic in Sub-Saharan Africa. The present study was carried out to examine the factors of HIV infection among women who lived in an urban area in Tanzania.

METHODS: The Tanzania HIV/AIDS and Malaria Indicator Survey (2011-12) data was used. The sample size for urban and rural women who had been tested for HIV and ever had sex was 2227 and 6210 respectively. Bivariate and multivariate logistic regression analyses were used.

RESULTS: The present study found that rural women were significantly less likely to be HIV-infected compared to urban women $(O R=0.612, p<0.00)$. About $10 \%$ urban women were $H I V$-infected whereas $5.8 \%$ women in rural areas were HIV positive. Women who had more than five sex partners were significantly four times more likely to be HIV-infected as compared to women who had one sex partner $(O R=4.49, p<0.00)$.

CONCLUSION: The results of this study suggest that less-educated women, women belonging to poor or poorer quintile, women spending nights outside and women having more than one sex partner were significantly more likely to have HIV infection among urban women as compared to rural women. There is an urgent need for a short and effective program to control the HIV epidemic in urban areas of Tanzania especially for less-educated urban women.

KEYWORDS: Women, Urban, HIV/AIDS, Tanzania, Africa, Monitoring
\end{abstract}

DOI:http://dx.doi.org/10.4314/ejhs.v25i4.5

\section{INTRODUCTION}

About 3.1 million people were newly infected with HIV cases in 2001, as compared to about 2.7 million (15\% fewer than 2001) people being newly infected in 2010 (1). During 2001 to 2009, the incidence of HIV infection declined in 33 countries, among which 22 countries are located in Sub-Saharan Africa (2). Globally, in 2009, about $72 \%$ HIV-related deaths occurred in Sub-Saharan Africa, even with the exertions of antiretroviral therapy $(3,4)$. Tanzania is the country hit the hardest by the HIV epidemic in Sub-Saharan Africa (3). According to the Tanzania HIV/AIDS and Malaria Indicators Survey (THMIS, 2007-08) report, the prevalence of HIV had decreased from $7.0 \%$ in 2004 to $5.8 \%$ in 2008 (6). However, the decrease was significant among men, but not among women $(2,6,7)$. Many recent studies have shown that the HIV epidemic is more likely to be prevalent among women than men due to biological difference, social disparities and lack of participation of men towards women's reproductive health $(2,8,9,10)$. According to the UNAIDS, about $52 \%$ adults living with HIV infection are women, and the rate of HIV infection among young women aged 15-24 years is persistently high (4). However, a few previous studies had found a high prevalence of HIV infection among urban women than in rural women (3). In 2011-12, the prevalence of HIV infection among women had decreased (11), but urban women still constituted a large proportion of

\footnotetext{
${ }^{1}$ International institute for Population Sciences, Mumbai, Maharashtra, India

Corresponding Author: Rakesh Kumar Singh, Email: rakeshiips5700@gmail.com; rakesh5700@iips.net
} 
the HIV-infected population. Therefore, the question regarding the factors responsible for the high HIV infection among urban women as compared to rural women was raised. Thus, there was a need to study the determinants of HIV infection among urban women in Tanzania.

\section{MATERIALS AND METHODS}

Data Sources: Tanzania HIV/AIDS and Malaria Indicator Survey (THMIS) was the third crosssectional population-based, comprehensive survey of HIV/AIDS carried out in Tanzania during 2011-12. The survey was conducted by the Tanzania Commission for AIDS (TACAIDS) and the Zanzibar AIDS Commission (ZAC) in collaboration with the National Bureau of Statistics (NBS), the Office of the Chief Government Statistician (OCGS), Zanzibar implemented THMIS, and ICF International provided technical assistance through MEASURE DHS (11). The objective of the survey was to monitor the trends of HIV infection among adults and behavioral risk factors for HIV. It was also designed to evaluate the ongoing programs and to develop new health strategies. The objective of the present study was to determine the prevalence of HIV infection among adult women (15-49 years) by their place of residence and the role of contributing factors to HIV infection among women in urban areas. Therefore, the sample size for urban and rural women who were tested for HIV and had ever had sex was 2227 and 6210 respectively. The THMIS had collected blood samples from women and men of 15-49 year age groups. During the survey, collection of dried blood sample was carried out for HIV testing under the supervision of senior staff members. Five-blood spots were collected on a filter paper from a finger prick of each participant. The DBS sample was sent to the Muhimbili University of Health and Allied Sciences (MUHAS) laboratory in Dar-E-Salam for storage and testing. The standard technique was adopted to maximize the sensitivity and specificity of HIV test results. The two different methods were used for HIV antibody enzyme-linked immunosorbent assays (ELISA), based on different antigens (11).

Sampling Method and Design: A multi-stage cluster sampling method was employed to recruit respondents in the survey (THMIS). The sampling frame was based on the 2002 Population and
Housing Census (PHC) that was developed by the National Bureau of Statistics (NBS). A similar sampling frame was used for the 2010 and 200405 Tanzania Demographic and Health Survey (TDHS) and THMIS (2007-08). The sampling frame excluded nomadic and institutional populations such as persons in hotels, barracks and prisons (11). A two-stage sample design was chosen where sample points (cluster) were selected in the first stage. A total of 583 clusters was selected from the enumeration areas (EAs), as defined in 2002 PHC. About 30-sample clusters were selected from Dar-E- Salam and 20 were selected in each of the other 24 regions. In Zanzibar, 15-sample clusters were selected in each of the five regions. The second stage of selection involved the systematic sampling of households listed from the selected clusters. Eighteen households were selected from each sample cluster from the total sample size of the 10,496 households (for detailed information, read report THMIS 2013) (11).

Description of Variables: Several variables were used in the study to understand the factors affecting the high prevalence of HIV among urban women. These variables are concisely explained in the following section.

Dependent variable: HIV serostatus was taken as the dependent variable. HIV Seropositive, coded as 1, was considered as the women having HIV infection, whereas HIV-seronegative, coded as 0 , was considered as the women not having HIV infection.

Independent Variables: The study included a set of predictor variables to examine their effect on the HIV prevalence. The study divided variables into three categories, namely socioeconomic, behavioral and biological characteristics. The variables are described as follows:

Socio-economic characteristics: Women's age groups in years $(15-19,20-24,25-29,30-34$, $35-39,40-44,45-49)$, age at first sex in years (below 16, 16-17,18-19, 20 and above), women's education level (no education, primary incomplete, primary complete, secondary and above education), wealth quintiles (poorer, poor, middle, rich, richest), regions (Eastern, Western, Southern, Southern highlands, South West highlands, Central, Northern, Lake and Zanzibar) 
Behavioral and biological characteristics: Number of nights spent outside in the last 12 months (1, 2, 3-4, 5 and above), number of sexual partners (1, 2, 3-4, 5-9, 10 and above), HIV status (HIV negative and HIV positive), condom used in the last 12 months (no, yes), had genital sore/ulcer in the last 12 months (no, yes), had genital discharge in the last 12 months (no, yes)

Statistical Analysis: The study used bivariate and multivariate techniques to understand the prevalence of HIV among women in association with their place of residence. Multivariate logistic regression analysis was applied to identify the effect of socioeconomic, behavioral and biological characteristics of women (15-49 years) on their HIV status. Logistic regression is commonly used when the independent variables include both numerical and nominal measures, and the outcome variables (dependent variables) are binary or dichotomous. The advantage of logistic regression analysis is that it requires no assumption about the distribution of the independent variables and the regression coefficient can be interpreted in terms of odds ratios. The complete analysis was performed by using statistical software STATA version10. 1 (StataCorp LP, College Station, Texas, USA).

\section{RESULTS}

\section{Prevalence of HIV among women living in urban and rural areas by background characteristics of urban and rural areas}

Table 1 reveals the prevalence of HIV infections among women (15-49 years) according to their socio-economic and behavioral characteristics varying with their place of residence in Tanzania, 2011-12. A larger percentage of women from urban areas who had been tested and had ever had sex were HIV positive (10\%) as compared to rural women $(5.8 \%)$. The risk of HIV increased with an increase in the age of women. About $11 \%$ women were found to be HIV positive that had first sex below the age of 16 years and lived in urban areas, which was much higher than that of women living in rural areas $(6 \%)$. The difference in the risk of acquiring HIV by women from rural and urban areas was observed by their level of education. For instance, more women with higher education from urban areas were HIV infected $(8.1 \%)$ than the women with higher education from rural areas $(5.3 \%)$. Urban women who had reported having two sexual partners were at three times more risk of becoming HIV positive (12.2\%) as compared to women with a single sexual partner $(4.4 \%)$. The risk of HIV infection became four times for women having five or more sexual partners as compared to that of women having a single sexual partner (16.6\%). In the Southern area of Tanzania, about $19 \%$ urban women were HIV positive, whereas $10.2 \%$ women from the rural areas were HIV positive. About $10 \%$ urban women, belonging to the Western Regions, Southwest Highlands, Lake and Central Regions were found to be HIV positive. Contrary to this, in rural areas of the Southern Highlands and Southwest Highlands, more than $10.0 \%$ of the women were found to be HIV positive. Zanzibar was the only region where the percentage of HIV infected $(1.2 \%)$ women were more in rural areas as compared to the urban areas, although the difference was very less (1.6\%).

Table 2 shows the association of HIV prevalence with the biological characteristics of women by their place of residence in Tanzania. About $10 \%$ urban women were HIV positive, whereas $5.8 \%$ rural women were HIV positive. About $17.3 \%$ urban and $20.3 \%$ rural women were HIV positive who had other sexually transmitted diseases in the last year. Among the urban women who had genital ulcer in the last year, about $22.5 \%$ were found to be HIV-infected, whereas the percentage decreased for rural women $(15.3 \%)$. 
Table 1: Prevalence of HIV among women aged 15-49 years who were tested and ever had sex, according to socio-demographic, behavioral characteristics in Tanzania, THMIS, 201112

\begin{tabular}{|c|c|c|c|c|c|c|}
\hline \multirow{2}{*}{$\begin{array}{l}\text { Background } \\
\text { Characteristics }\end{array}$} & \multicolumn{2}{|c|}{ Urban } & \multirow{2}{*}{$\begin{array}{c}\text { Urban Sample } \\
\text { Size }\end{array}$} & \multicolumn{2}{|c|}{ Rural } & \multirow{2}{*}{$\begin{array}{c}\text { Rural Sample } \\
\text { Size }\end{array}$} \\
\hline & HIV- & HIV+ & & HIV- & HIV+ & \\
\hline \multicolumn{7}{|l|}{ Age in 5-year groups } \\
\hline $15-19$ & 98.1 & 1.9 & 251 & 98.5 & 1.5 & 767 \\
\hline $20-24$ & 93.1 & 6.9 & 403 & 96.3 & 3.7 & 1154 \\
\hline $25-29$ & 90.2 & 9.8 & 521 & 94.2 & 5.8 & 1142 \\
\hline $30-34$ & 86.8 & 13.2 & 382 & 92.3 & 7.7 & 932 \\
\hline $35-39$ & 87 & 13 & 292 & 93.5 & 6.5 & 973 \\
\hline $40-44$ & 88.6 & 11.4 & 219 & 91.4 & 8.6 & 682 \\
\hline $45-49$ & 82.7 & 17.3 & 161 & 91.8 & 8.2 & 559 \\
\hline \multicolumn{7}{|l|}{ Age at first sex } \\
\hline$<16$ & 88.7 & 11.3 & 762 & 94 & 6 & 2717 \\
\hline $16-17$ & 90.4 & 9.6 & 265 & 95.8 & 4.2 & 933 \\
\hline $18-19$ & 90.5 & 9.5 & 651 & 94.7 & 5.3 & 1519 \\
\hline $20+$ & 90.8 & 9.2 & 547 & 92.6 & 7.4 & 1041 \\
\hline \multicolumn{7}{|l|}{ Women's Education } \\
\hline No education & 90.2 & 9.8 & 150 & 94.9 & 5.1 & 1495 \\
\hline Primary incomplete & 88 & 12 & 174 & 93.4 & 6.6 & 869 \\
\hline Primary complete & 89.2 & 10.8 & 1302 & 94 & 6 & 3348 \\
\hline Secondary+ & 91.9 & 8.1 & 602 & 94.7 & 5.3 & 499 \\
\hline \multicolumn{7}{|l|}{ Wealth index } \\
\hline Poorest & 82.5 & 17.5 & 47 & 95.3 & 4.7 & 1465 \\
\hline Poorer & 100 & 0 & 39 & 94.7 & 5.3 & 1541 \\
\hline Middle & 89.5 & 10.5 & 93 & 94 & 6 & 1452 \\
\hline Richer & 87.3 & 12.7 & 445 & 93.8 & 6.2 & 1272 \\
\hline Richest & 90.7 & 9.3 & 1604 & 91.2 & 8.8 & 479 \\
\hline \multicolumn{7}{|c|}{$\begin{array}{l}\text { Number of night spent } \\
\text { outside (last } 12 \text { months) }\end{array}$} \\
\hline None & 91.3 & 8.7 & 889 & 95.2 & 4.8 & 3680 \\
\hline $1-2$ & 89.7 & 10.3 & 969 & 92.7 & 7.3 & 1943 \\
\hline $3-4$ & 87 & 13 & 254 & 94.1 & 5.9 & 446 \\
\hline $5+$ & 88.4 & 11.6 & 117 & 89.4 & 10.6 & 141 \\
\hline \multicolumn{7}{|c|}{ Number of sexual partner } \\
\hline 1 & 95.6 & 4.4 & 752 & 97.5 & 2.5 & 2885 \\
\hline 2 & 87.8 & 12.2 & 585 & 92.6 & 7.4 & 1618 \\
\hline $3-4$ & 88.6 & 11.4 & 612 & 90.8 & 9.2 & 1232 \\
\hline $5-9$ & 83.2 & 16.8 & 180 & 87.9 & 12.1 & 402 \\
\hline $10+$ & 73.4 & 26.6 & 68 & 90.4 & 9.6 & 56 \\
\hline \multicolumn{7}{|l|}{ Region } \\
\hline Eastern & 90.8 & 9.2 & 841 & 93.6 & 6.4 & 462 \\
\hline Western & 88.2 & 11.8 & 164 & 95.8 & 4.2 & 507 \\
\hline Southern & 90.8 & 9.2 & 148 & 96.1 & 3.9 & 310 \\
\hline Southern Highlands & 81 & 19 & 153 & 89.8 & 10.2 & 790 \\
\hline South West Highlands & 87.3 & 12.7 & 147 & 89.8 & 10.2 & 682 \\
\hline Central & 89.3 & 10.7 & 93 & 97.4 & 2.6 & 769 \\
\hline Northern & 93.4 & 6.6 & 244 & 95.8 & 4.2 & 698 \\
\hline Lake & 89.4 & 10.6 & 369 & 94.8 & 5.2 & 1825 \\
\hline Zanzibar & 98.8 & 1.2 & 68 & 98.4 & 1.6 & 167 \\
\hline Total & & & 2227 & & & 6210 \\
\hline
\end{tabular}


Table 2: Prevalence of HIV among women aged 15-49 years who were tested and ever had sex, according to biological characteristics in Tanzania, THMIS, 2011-12

\begin{tabular}{|c|c|c|c|c|c|c|}
\hline \multirow{2}{*}{$\begin{array}{l}\text { Background } \\
\text { Characteristics }\end{array}$} & \multicolumn{2}{|c|}{ Urban } & \multirow{2}{*}{$\begin{array}{c}\text { Urban Sample } \\
\text { Size }\end{array}$} & \multicolumn{2}{|c|}{ Rural } & \multirow{2}{*}{$\begin{array}{c}\text { Rural Sample } \\
\text { Size }\end{array}$} \\
\hline & HIV- & HIV+ & & HIV- & HIV+ & \\
\hline \multicolumn{7}{|l|}{ HIV status } \\
\hline No & 89.9 & - & 2003 & 94.2 & - & 5851 \\
\hline Yes & - & 10.1 & 224 & - & 5.8 & 359 \\
\hline \multicolumn{7}{|c|}{ STI in last 12 months } \\
\hline No & 90.4 & 9.6 & 2116 & 94.6 & 5.4 & 5996 \\
\hline Yes & 82.7 & 17.3 & 94 & 79.8 & 20.2 & 164 \\
\hline \multicolumn{7}{|c|}{$\begin{array}{l}\text { Had genital sore/ulcer } \\
\text { (last } 12 \text { months) }\end{array}$} \\
\hline No & 90.3 & 9.7 & 2152 & 94.5 & 5.5 & 6015 \\
\hline Yes & 77.5 & 22.5 & 72 & 84.7 & 15.3 & 187 \\
\hline \multicolumn{7}{|c|}{$\begin{array}{l}\text { Had genital discharge } \\
\text { (last } 12 \text { months) }\end{array}$} \\
\hline No & 90.1 & 9.9 & 2084 & 94.5 & 5.5 & 5879 \\
\hline Yes & 87.1 & 12.9 & 140 & 89.6 & 10.4 & 323 \\
\hline Total & & & 2227 & & & 6210 \\
\hline
\end{tabular}

Risk factors for HIV infections from Multivariate Logistic Regression Analyses

Results: Table 3 presents the risk factors of HIV infection among all women who were tested and had ever had sex in model 1 . Model 2 shows risk factors of the HIV infection among urban women, and model 3 shows risk factors of HIV infection among rural women, after controlling for selected socioeconomic, behavioural and biological characteristics of women.

Model 1 found that rural women who were tested and had ever had sex were significantly less likely to be HIV-infected $(\mathrm{OR}=0.612, \mathrm{p}<0.001)$ as compared to urban women. Women, belonging to upper age groups (45-49 years), were four times more likely to be HIV-infected $(\mathrm{OR}=4.571$, $\mathrm{p}<0.001)$ compared to women of younger age groups (15-19 years). Women with secondary or higher education were significantly less likely at risk of getting HIV $(\mathrm{OR}=0.680, \mathrm{p}<0.01)$ as compared to non-educated or low-educated women. Women who had more than two sexual partners were significantly three times more likely to be HIV-infected (3-4 partners, $\mathrm{OR}=3.535$, $\mathrm{p}<0.001 ; 5-9$ partner, OR $=4.491, \mathrm{p}<0.001 ; 10+$ partner, $\mathrm{OR}=4.682, \mathrm{p}<0.001)$ compared to women who had a single sexual partner. Women who had spent the night outside more than five times in the last one year were found to be four times more likely to be HIV-infected than the women who did not spend a single night outside the home.

From model 2, we found that urban women who had first sex after the age of 20 years were significantly less likely to be HIV infected $(\mathrm{OR}=$ $0.571, \mathrm{p}<0.01)$ compared to women who had first sex before the age of 16 years. In urban areas, women who had spent the night outside the home (more than 3 to 4 times) in the last 12 months, were more likely to be HIV positive (OR $=1.577$, $\mathrm{p}<0.01)$ compared to women who had not spent a single night outside the home. Urban women who had more than two sexual partners were two times more likely to get HIV-infected (2 sexual partners, $\mathrm{OR}=2.09, \mathrm{p}<0.01 ; 3$ to 4 sexual partners, OR = $2.069, \mathrm{p}<0.01)$ compared to women who had a single sexual partner. Women, who had any one STI/Ds in last 12 months, were more likely to be HIV-infected compared to women who did not have any STIs. Those women who had above secondary education were less likely to be HIVinfected compared to the women who had less or were primary educated. 
Table 3: Logistic regression analysis results for HIV infection among women aged 15-49 years who were tested and ever had sex in Tanzania, THMIS, 2011-12.

\begin{tabular}{|c|c|c|c|c|c|c|}
\hline $\begin{array}{l}\text { Background } \\
\text { Characteristics }\end{array}$ & $\begin{array}{c}\operatorname{Exp}(\boldsymbol{\beta}) \\
\text { Model } 1 \\
\text { (Combine) }\end{array}$ & $\begin{array}{c}95 \% \text { C.I. for } \\
\operatorname{Exp}(\beta) \\
\text { (lower, upper) }\end{array}$ & $\begin{array}{c}\operatorname{Exp}(\boldsymbol{\beta}) \\
\text { Model } 2 \\
\text { (Urban) }\end{array}$ & $\begin{array}{l}95 \% \text { C.I. for } \\
\operatorname{Exp}(\beta) \\
\text { lower, upper }\end{array}$ & $\begin{array}{c}\operatorname{Exp}(\boldsymbol{\beta}) \\
\text { Model } 3 \\
\text { (Rural) }\end{array}$ & $\begin{array}{l}95 \% \text { C.I. for } \\
\operatorname{Exp}(\beta) \\
\text { lower, upper }\end{array}$ \\
\hline \multicolumn{7}{|l|}{ Place of residence } \\
\hline Urban $^{\circledR}$ & 1 & & & & & \\
\hline Rural & $0.612 * * *$ & $0.491,0.763$ & & & & \\
\hline \multicolumn{7}{|l|}{$\begin{array}{l}\text { Women's age groups } \\
\text { (years) }\end{array}$} \\
\hline $15-19^{\circledR}$ & 1 & & 1 & & 1 & \\
\hline $20-24$ & $2.138 * *$ & $1.216,3.758$ & $2.721 * *$ & $1.088,6.804$ & $2.139 * *$ & $1.069,4.282$ \\
\hline $25-29$ & $2.555^{* *}$ & 1.468 .4 .446 & $3.649 * *$ & $1.474,9.03$ & $2.446 *$ & $1.231,4,858$ \\
\hline $30-34$ & $4.688 * * *$ & $2.722,8.075$ & $7.143 * * *$ & $2.912,17.521$ & $4.321 * * *$ & $2.211,8.445$ \\
\hline $35-39$ & $3.869 * * *$ & $2.218,6.75$ & $7.251 * * *$ & $2.914,18.04$ & $3.322 * * *$ & $1.668,6.616$ \\
\hline $40-44$ & $3.471 * * *$ & $1.93,6.243$ & $6.888 * * *$ & $2.696,17.595$ & $3.379 * * *$ & $1.651,6.915$ \\
\hline $45-49$ & $4.571 * * *$ & $2.531,8.255$ & $7.464 * * *$ & $2.838,19.632$ & $4.107 * * *$ & $1.996,8.449$ \\
\hline \multicolumn{7}{|l|}{ Age at first sex } \\
\hline$<16^{\circledR}$ & & & 1 & & 1 & \\
\hline $16-17$ & 0.889 & $0.645,1.224$ & 1.051 & $0.668,1.653$ & 0.801 & $0.536,1.199$ \\
\hline $18-19$ & 0.962 & $0.747,1.239$ & 0.936 & $0.664,1.319$ & 0.92 & $0.666,1.272$ \\
\hline $20+$ & 1.203 & $0.899,1.609$ & $0.571 * *$ & $0.379,0.86$ & $1.612 * *$ & $1.134,2.293$ \\
\hline \multicolumn{7}{|l|}{ Women's education } \\
\hline No education ${ }^{\circledR}$ & 1 & & 1 & & 1 & \\
\hline Primary incomplete & 1.257 & $0.876,1.804$ & 0.837 & $0.429,1.632$ & 1.334 & $0.883,2.016$ \\
\hline Primary complete & 1.234 & $0.922,1.652$ & 0.76 & $0.439,1.316$ & 1.369 & $0.975,1.923$ \\
\hline Secondary+ & $0.633^{*}$ & $0.477,0.841$ & $0.328 * *$ & $0.172,0.624$ & 0.814 & $0.444,1.494$ \\
\hline \multicolumn{7}{|l|}{ Wealth quintiles } \\
\hline Poorer $^{\circledR}$ & 1 & & 1 & & 1 & \\
\hline Poor & 1.19 & $0.821,1.725$ & 0.882 & $0.179,4.332$ & 1.234 & $0.845,1.804$ \\
\hline Middle & $1.342 *$ & $0.937,1.922$ & 1.96 & $0.573,6.708$ & 1.304 & $0.897,1.897$ \\
\hline Rich & 1.378 & $0.967,1.965$ & 1.835 & $0.624,5.39$ & 1.196 & $0.806,1.775$ \\
\hline Richer & $1.268 * *$ & $0.838,1.92$ & 1.637 & $0.564,4.753$ & 1.483 & $0.873,2.518$ \\
\hline \multicolumn{7}{|l|}{$\begin{array}{l}\text { Number of night spent } \\
\text { outside(last } 12 \text { months) }\end{array}$} \\
\hline None $^{\circledR}$ & 1 & & 1 & & 1 & \\
\hline $1-2$ & $1.310^{* *}$ & $1.055,1.628$ & $1.485^{*}$ & $1.077,2.047$ & 1.197 & $0.917,1.562$ \\
\hline $3-4$ & 1.271 & $0.9,1.794$ & $1.577 *$ & $1.013,2.454$ & 0.911 & $0.562,1.477$ \\
\hline $5+$ & 1.168 & $0.702,1.941$ & 0.847 & $0.497,1.443$ & 1.312 & $0.658,2.619$ \\
\hline \multicolumn{7}{|l|}{$\begin{array}{l}\text { Number of sexual } \\
\text { partner }\end{array}$} \\
\hline $1^{\circledR}$ & 1 & & 1 & & 1 & \\
\hline 2 & $3.249 * * *$ & $2.426,4.351$ & $2.09^{* *}$ & $1.267,3.447$ & $3.702 * * *$ & $2.613,5.246$ \\
\hline $3-4$ & $3.535 * * *$ & $2.614,4.778$ & $2.069 * *$ & $1.268,3.378$ & $4.407 * * *$ & $3.061,6.344$ \\
\hline $5-9$ & $4.491 * * *$ & $3.106,6.494$ & $2.125 * *$ & $1.232,3.666$ & $5.093 * *$ & $3.225,8.042$ \\
\hline $10+$ & $4.682 * * *$ & $2.5,8.768$ & $2.203 * *$ & $1.218,3.986$ & $2.549 * * *$ & $0.85,7.645$ \\
\hline \multicolumn{7}{|c|}{ Condom used (last year) } \\
\hline $\mathrm{No}^{\circledR}$ & 1 & & 1 & & 1 & \\
\hline Yes & $2.868 * * *$ & $2.267,3.628$ & $2.833 * * *$ & $2.09,3.841$ & $2.766^{* * *}$ & $2.032,3.765$ \\
\hline \multicolumn{7}{|l|}{ STI in last 12 month } \\
\hline $\mathrm{No}^{\circledR}$ & 1 & & 1 & & 1 & \\
\hline Yes & $2.737 * *$ & $1.854,4.042$ & $1.708^{* *}$ & $0.975,2.993$ & $3.164 * * *$ & $1.964,5.098$ \\
\hline
\end{tabular}

®-Reference category of different characteristics; ***p $<0.001, * * \mathrm{p}<0.01, * \mathrm{p}<0.05$ 
Model 3 reveals that rural women who belonged to upper age groups (35-39, 40-44, and 45-49 years) were significantly more likely to have HIV infection $(\mathrm{OR}=3.322,3.379$, and 4.107, $\mathrm{p}<0.000)$ compared to younger age groups (15-19 years) women. Those respondents who had first sex after the age of 20 years were more likely to have HIV infection as compared to respondents who had first sex below the age of 16 years. In rural areas, women who had more than two sexual partners were five times more likely $(\mathrm{OR}=4.407, \mathrm{p}<0.000)$ to have HIV infection compared to women who had less than 2 sexual partners.

\section{DISCUSSION}

The prevalence of HIV has declined in Tanzania during the last decade $(3,4)$. This trend was also similar to the trends apparent in Eastern and Southern African countries like Uganda, Malawi, Zimbabwe and Kenya $(12,13,14,15,16,17)$. A recent survey report (THMIS, 2011-12) found a higher prevalence of HIV infection among women (6.2\%) than among men $(3.8 \%)$ in Tanzania. This study found that among urban women (15-49 years) who were tested for HIV and had ever had sex, HIV prevalence was higher (10.01\%) compared to rural women (5.8\%). Mmbaga (2013)had revealed that women in urban areas were at a greater risk of acquiring HIV. Similar to the results of a previous study (3), the findings of this study revealed that the risk of getting HIV increased as woman's age increased. Women with secondary and higher education were less likely to be HIV-infected as compared to uneducated women. Educated people were at a higher risk of getting HIV as compared to uneducated women as educated persons move to other places more frequently. They can also afford paid sex $(18,19,20)$. However, intervention or prevention program against HIV infection had reduced HIV prevalence among educated women (21).

In Africa, the prevalence of HIV/AIDS had decreased due to the behavioral change (16). Women who spent two or more nights outside in the last 12 months were found more likely to be HIV-infected than women who did not spend a night outside in urban areas. Similarly, women who had two or more sexual partners were three times more HIV-infected than those who had a single sexual partner. The findings of the present study are consistent with the findings of other research $(3,16)$. The studies had reported that reducing the number of sexual partners had decreased the risk of HIV transmission $(13,22,23)$. In the previous studies, researchers had found that young females, married individuals and those who had higher education were at higher risk of HIV infection compared to other groups in Tanzania $(24,25)$.

This study forwarded the notion that urban women were at a higher risk of getting HIV infection than rural women in Tanzania. Our analysis showed a strong and consistent effect of behavioral characteristics on the risk of the HIV infection among urban women. The risk of HIV infection was higher among uneducated or lesseducated women, among women with two or more sex partners, among women who spent a night outside and had other other STD's. Therefore, prevention programs aimed to reduce HIV infection among urban women are the utmost requirements. The program should focus on awareness-raising and on behavioral transformation of urban women in terms of reducing the practice of multiple sexual partnership. The appropriate strategy is also needed to ensure the women's attainment of education, at-least up to the secondary level. Moreover, planning to provide employment to the urban women can reduce their vulnerability and exposure to paid sex.

\section{REFERENCES}

1. Ubesie AC. Pediatric HIV/AIDS in Sub-Saharan Africa: Emerging issues and way forward. African Health Sciences. 2012; 12(3):297-304.

2. WHO; UNAIDS and UNICEF. Global HIV/AIDS Response: Epidemic update and Health Sector Progress Towards Universal Access: Progress report 2011; WHO; UNAIDS and UNICEF available www.who.int/hiv/pub/progress_report2011/en

3. Mmbaga EJ.HIV Prevalence and Associated Risk Factors: Analysis of Change over Time in Mainland Tanzania.DHS Working Paper; 2013 No. 85.

4. UNAIDS, WHO. AIDS Epidemic Update. 2010; Washington D.C., USA: USAID.

5. Tanzania Commission for AIDS (TACAIDS), Zanzibar AIDS Commission (ZAC), National Bureau of Statistics (NBS), Office of the Chief Government Statistician (OCGS), and Macro 
International Inc. 2008. Tanzania HIV/AIDS and Malaria Indicator Survey 2007-08. Dar es Salaam, Tanzania: TACAIDS, ZAC, NBS, OCGS, and Macro International Inc.

6. Urassa W, Kaaya S, Mwakagile D, O'Brien M, Antelman G, Hunter D, Fawzi W, Msamanga G. Evidence of a Substantial Decline in Prevalence of HIV-1 Infection among Pregnant Women: Data from 1995 to 2003 in Dar es Salaam, Tanzania. Scand J Public Health. 2006; 34(3): 272-8.

7. Kwesigabo G, Killewo JZ, Sandstorm A. Sentinel Surveillance and Cross Sectional Survey on HIV Infection Prevalence: A Comparative Study. East Afr Med J. 1996;73(5): 298-302.

8. Boerma JT, Gregson S, Nyamukapa C, Urassa M. Understanding the Uneven Spread of HIV within Africa: A Comparative Study of Biologic, Behavioral, and Contexual Factors in Rural Population in Tanzania and Zimbabwe. Sexually Transmitted Diseases.2003;30(10): 779-87.

9. Mnyika KS et al. Risk Factors for HIV-1 Infection among Women in the Arusha Region of Tanzania.J Acquir Immune DeficSyndr Hum Retrovirol1996;11(5): 484-9.

10. Royce RA, Sena A, Cates W, CohenMS. Sexual Transmission of HIV. N Eng J Med 1997; 336: 1072-8.

11. Tanzania HIV/AIDS and Malaria Indicator Survey 2011-12.Dar es Salaam, Tanzania: TACAIDS, ZAC, NBS, OCGS, and ICF International.Tanzania HIV/AIDS and Malaria Indicator Survey 201112.Dar es Salaam, Tanzania: TACAIDS, ZAC, NBS, OCGS, and ICF International.

12. Asamoah-Odei E, Garcia JM,Calleja, Boerma JT. HIV Prevalence and Trends in Sub-Saharan Africa: No Decline and Large Subregional Differences. Lancet.2004;364(9428): 35-40.

13. Fylkenes K, Musonda RM, Sichone M, Ndhlovu Z, Tembo F, Monze M. Declining HIV Prevalence and Risk Behaviours in Zambia: Evidence from Surveillance and Population-Based Surveys. AIDS 2001; 15(7): 907-16.

14. Gregson, S. et al. HIV Decline Associated with Behaviour Change in Eastern Zimbabwe. Science.2006;311(5761): 664-6.

15. Hallett, TB. Declines in HIV Prevalence Can Be Associated with Changing Sexual Behaviour in Uganda, Urban Kenya, Zimbabwe and Urban Haiti." Sexually Tansmitted Infection.2006;82(Suppl 1): i1-8.

16. Kirungi WL. et al. Trends in Antenatal HIV Prevalance in Urban Uganda Associated with Uptake of Preventive Sexual Behaviours. Sexually Transmitted Infection.2006;82(Suppl 1):36-41.
17. Michelo C, Sandoy IF, Fylkesnes K. Marked HIV Prevalence Declines in Higher Educated Young People: Evidence from Population-Based Surveys (1995-2003) in Zambia.AIDS. 2006; 20(7): 10318.

18. Tanzania Commission for AIDS (TACAIDS), NBS \& ORC Macro. (2005). Tanzania HIV/AIDS Indicator Survey 2003-04. Calverton, Maryland, USA: TACAIDS, NBS \& ORC Macro.

19. MmbagaEJ et al. Trends in HIV-1 Prevalence and Risk Behaviours over 15 Years in a Rural Population in Kilimanjaro, Tanzania. AIDS Research and Therapy 2007;4: 23.

20. Hargreaves JR, Glynn JR. Educational Attainment and HIV-1 Infection in Developing Countries: A Systematic Review. Trop Med Int Health.2002;7(6): 489-98.

21. Coombe C, Kelly MJ. Education as a Vehicle for Combating HIV/AIDS.Prospects. 2001; 31(3): 435445.

22. Killian AH. et al. Reduction in Risk Behaviours Provides the Most Consistent Explanation for the Declining HIV-1 Prevalence in Uganda. AIDS.1999; 13(3): 391-8.

23. Kapiga SH, Aitken LW.Role of Sexually Transmitted Diseases in HIV-1 Transmission.In AIDS in Africa, edited by M. Essex, S. Mboup, P.J. Kanki, R.G. Marlink, S.D. Tlou, and M. Holme, 2002; 231-250. New York, NY, USA: Kluwer Academic/Plenum

24. Mmbaga EJ, Hussain A, Leyna G,et al.Incidence of HIV-1 infectionand changes in the prevalence of reproductive tractinfection and sexual risk behaviours: a population based longitudinalstudy in rural Tanzania. AJAR 2006;(5):281-287.

25. Mmbaga EJ, Hussain A, Leyna G, et al. Prevalence and Risk Factors for HIV-I infection in rural Kilimanjaro region of Tanzania: Implications for Prevention and Treatment. BMC Public Health. 2007; (7):58. 